\title{
Lung Phosphatidylcholine Synthesis and Cholinephosphotransferase Activity in Anencephalic Rat Fetuses with Corticosteroid Deficiency
}

\author{
PHILIP M. FARRELL, ${ }^{(26)}$ WILL R. BLACKBURN, AND ANTHONY J. ADAMS
}

Neonatal and Pediatric Medicine Branch, National Institute of Child Health and Human Development, National Institutes of Health, Bethesda, Maryland, and Departments of Pediatrics and Pathology, University of South

Alabama, Mobile, Alabama, USA

\begin{abstract}
Summary
Adrenocortical insufficiency was produced in rat fetuses by surgical decapitation. These animals show low plasma corticosterone levels compared to littermate controls. Lung slices from anencephalic fetuses were found to have reduced incorporation of $\left\{{ }^{14} \mathrm{C}\right]$ choline into phosphatidylcholine, hence diminished choline pathway activity; this abnormality was present at 21 days of gestation but not at term. Cholinephosphotransferase (CPT), the terminal catalyst of the choline pathway, also showed diminished activity in lungs of anencephalic fetuses, with a mean of $120 \mathrm{pmol} / \mathrm{min} / \mathrm{mg}$ protein compared to a control value of 190 . Dexamethasone treatment of these animals for 6-12 hr led to enhanced choline incorporation rates. Corticosteroid administration also restored CPT activity and even elevated the enzyme to a mean level $(340 \mathrm{pmol} / \mathrm{min} / \mathrm{mg}$ protein) greater than that found in normal fetuses at 21-22 days of gestation. The early pulmonary biochemical effects of dexamethasone in this model were not accompanied by recognizable ultrastructural changes.
\end{abstract}

\section{Speculation}

It is proposed that glucocorticoids act to influence the timing of lung biochemical development relative to phosphatidylcholine synthesis. Increased amounts of the hormone appear to be sufficient but not necessary for this effect since augmented choline pathway rates eventually occur in the absence of the corticosteroid stimulus.

The low surface tension achieved during expiration by the pulmonary surfactant system is essential for maintenance of alveolar integrity and prevention of the neonatal respiratory distress syndrome $(1,8)$. Synthesis of the major surfactant phospholipid, phosphatidylcholine PC or lecithin (1,2-diacyl-sn-glycero-3-phosphorylcholine), is accomplished de novo in fetal lung by incorporation of CDP-choline into 1,2-diacylglycerol $(7,9)$. Investigations by several groups with many species have demonstrated that corticosteroids influence fetal lung development, leading to early increases in the following: (1) functional surfactant (19), (2) PC concentration (11), (3) PC synthesis per se from choline $(6,11)$, and (4) the apparent number of osmiophilic lamellar bodies in type II pneumonocytes (25). Such maturational changes are accompanied by, and are at least partially attributable to, corticosteroid-mediated induction of cholinephosphotransferase or CPT (CDP-choline: 1,2-diglyceride choline phosphotransferase, EC. 2.7.8.2) (11).

Although adrenocortical insufficiency is rarely encountered in developing fetuses, Jost and Picon (18) have described a model of fetal panhypopituitarism which is produced surgically by de- capitating rat fetuses prior to the 18 th day of gestation. This experimental model has provided considerable information on the role of adrenocorticoids in regulating liver glycogen metabolism (15) and has been employed by Blackburn and associates $(2,3)$ to investigate fetal lung development. In the latter studies, it has been demonstrated that lungs of anencephalic rat fetuses show: (1) morphologic abnormalities characterized by increased cellularity, retarded cytodifferentiation, and a decreased number of osmiophilic lamellar bodies in type II pneumonocytes; (2) functional impairment evidenced by an inability of minced lung samples to lower surface tension to normal levels, suggesting surfactant deficiency, and (3) chemical changes, including a decreased concentration of lung phosphatidylcholine and a reduction in the palmitic acid content of isolated PC.

In the present investigation, after confirming the presence of plasma corticosteroid deficiency in decapitated fetuses, we have examined the lungs of such animals biochemically by measuring phosphatidylcholine synthesis in vitro and by determining cholinephosphotransferase. In addition, lung PC production and CPT activity were measured 6-12 hr after in utero administration of dexamethasone and the findings compared with the ultrastructural appearance of lung tissue.

\section{MATERIALS AND METHODS}

Pregnant Sprague-Dawley rats with accurately timed gestations (within $12 \mathrm{hr}$ ) were obtained from Charles River Laboratories. The animals were anesthetized with ether and subjected to surgery at 16-17 days gestation as described previously $(2,3)$. Following decapitation of half the fetuses per litter (the remainder serving as controls), fetuses were generally allowed to develop without further intervention until harvesting. Delivery by cesarean section was carried out between 19.5 and 22 days of gestation (term for this species is 22 days). At the time of death, gestational ages were confirmed by weighing control fetuses and comparing the mean body weight per litter with previously established data on fetal weight as a function of gestational age (2). The lungs were then rapidly removed and either placed in chilled saline for a few minutes prior to slicing, frozen on dry ice for later enzyme assays, or added to $3 \%$ glutaraldehyde in cacodylate buffer ( $\mathrm{pH} 7.8$ ) for electron microscopic studies. In a limited number of fetuses delivered at the same time of the day (2 PM), blood samples were collected with heparinized capillary tubes, centrifuged; and frozen for corticosterone analysis.

In addition to controls of various gestational ages and untreated anencephalic rat fetuses, a number of the latter animals were administered $1.5 \mu \mathrm{g}$ dexamethasone by intraperitoneal injection with a Hamilton microsyringe. The glucocorticoid was given at 20.5 or 21.5 days of gestation, at which time the dose is 
equivalent to $0.4 \mu \mathrm{g} / \mathrm{g}$ body weight. on the average. In order to quantitate pulmonary uptake of steroid in groups of animals where lung CPT was to be measured, $0.5 \mu \mathrm{Ci}$ [1.2.4${ }^{3} \mathrm{H}(\mathrm{N})$ \}dexamethasone $(1 \mathrm{mCi} / \mathrm{ml}, 31.2 \mathrm{Ci} / \mathrm{mmol})$ was included per $75-\mu l$ injection. The specific activity of $\left[{ }^{3} \mathrm{H}\right]$ dexamethasone was determined precisely for each batch of administered glucocorticoid by liquid scintillation counting. Treated fetuses were delivered $6-12 \mathrm{hr}$ after corticosteroid administration and lungs were removed and processed for the analyses described below.

Lung phosphatidylcholine synthesis was measured in vitro as described in detail elsewhere $(10,11)$. Briefly, lung samples were sliced on a Stadie-Riggs microtome and then placed in a flask containing $4 \mathrm{ml}$ Krebs-Ringer bicarbonate solution at $\mathrm{pH}$ 7.4. After a 5 -min preincubation, $2 \mu \mathrm{Ci}\left[{ }^{14} \mathrm{C}\right]$ choline chloride $(60 \mathrm{mCi} / \mathrm{mmol})$ were added and tissues incubated for $1 \mathrm{hr}$ at $37^{\circ}$ under $95 \% 0_{2} / 5 \% \mathrm{CO}_{2}$. Subsequently, lipids were extracted by the technique of Folch et al . (12) and incorpation of isotope into $\mathrm{PC}$ was determined with the aid of thin layer chromatography on silica gel $\mathrm{H}$ (developing solvent: $\mathrm{CHCL}_{3} / \mathrm{CH}_{3} \mathrm{OH} / \mathrm{H}_{2} \mathrm{O}, 130 / 50$ / 8).

Cholinephosphotransferase activities were determined on lung samples frozen at $-30^{\circ}$ for $1-2$ weeks and homogenized in 5 volumes of $0.05 \mathrm{M}$ Tris- $\mathrm{HCl}(\mathrm{pH} \mathrm{8.0)}$ containing $5 \mathrm{mM}$ EDTA and $10 \mathrm{mM}$ dithiothreitol. The enzyme was measured using a technique described elsewhere (10). Components of the $0.5-\mathrm{ml}$ reaction mixture included $30 \mathrm{mM}$ Tris- $\mathrm{HCl}(\mathrm{pH} 8.0), 15 \mathrm{mM}$ $\mathrm{MgCl}_{2}, 0.002 \%$ Triton X-100, $1 \mathrm{mM} \mathrm{1,2-dipalmitoyl} \mathrm{glycerol,}$ and $2 \mathrm{mM}$ CDP-choline containing $0.6 \mu \mathrm{Ci} / \mu \mathrm{mol}{ }^{14} \mathrm{C}$-labeled substrate. $\left[{ }^{3} \mathrm{H}\right]$ Dexamethasone was quantitated in lungs from corticosteroid-treated fetuses by scintillation counting of digested tissues. For digestion, $0.3-\mathrm{ml}$ aliquots of $20 \%$ lung homogenates were added to glass vials containing $2 \mathrm{ml}$ Protosol and the samples were incubated for $2-3 \mathrm{hr}$ at $55^{\circ}$. After cooling and addition of $10 \mathrm{ml}$ Aquasol, the vials were placed in the scintillation counter and allowed to stand until chemiluminescence disappeared; tritium was then measured at $30 \%$ efficiency. From the determined specific activity of injected $\left[{ }^{3} \mathrm{H}\right]$ dexamethasone, the amount of exogenous corticosteroid per lung was calculated to provide an estimate of pulmonary uptake.

Corticosterone was determined in pooled plasma samples collected from the cervical vessels of a limited number of fetuses. Two sample pools sufficient for corticosteroid analyses were obtained from anencephalic animals and two from littermate controls. The competitive protein binding radioassay of Murphy (23) was employed with minor modifications for this measurement. The protein concentration of lung homogenates used for CPT assays was determined by the technique of Lowry et al. (22). Liquid scintillation counting was carried out in a Beckman LS-255 instrument; counting efficiencies for $\left[{ }^{3} \mathrm{H}\right]$ dexamethasone and $\left[{ }^{14} \mathrm{C}\right]$ phosphatidylcholine were determined by internal standardization. Tissues for cytologic studies, initially fixed in glutaraldehyde, were postfixed in buffered $1 \%$ osmium tetroxide, dehydrated in ethanol, embedded in Epon, and examined electron microscopically.

\section{RESULTS}

The corticosterone concentrations in pooled plasma samples from control and anencephalic fetuses of 20 days of gestation (dg) were 26 and $6.9 \mu \mathrm{g} / \mathrm{dl}$, respectively; corresponding values in fetuses of $22 \mathrm{dg}$ were 28 and $8.5 \mu \mathrm{g} / \mathrm{dl}$.

Data describing lung phosphatidylcholine synthesis from $\left[{ }^{14} \mathrm{C}\right]$ choline are given in Table 1 for groups of animals between 20.5 and $22 \mathrm{dg}$. It is evident that anencephalic fetuses show a statistically significant $(P<0.02)$ reduction in the conversion of choline to phospholipid. In reviewing our initial findings, however, we noted that a distinct difference existed between decapitated animals of 20.5-21.5 dg as compared to those delivered at term;i.e., in the last few hours of prenatal development. For this reason, the data for anencephalic fetuses were separated into two subgroups averaging either 21 or $22 \mathrm{dg}$ and additional fetuses were examined at these ages along with three animals of $19.5 \mathrm{dg}$. Results from such determinations are presented in Figure 1 along with observations in a series of 49 controls of various gestational ages. The rate of $\left[{ }^{14} \mathrm{C}\right]$ choline incorporation into $P C$ in 10 anencephalic animals averaging $21 \mathrm{dg}$ was found to be markedly reduced from $3650 \pm 230 \mathrm{cpm} / \mathrm{mg}$ lung/hr (mean \pm SE for 11 controls) to $2030 \pm 93(P<0.001)$. On the other hand, lung slices from 10 anencephalic fetuses of $22 \mathrm{dg}$ showed a rate of $4070 \pm 246$ and were not significantly different from 11 controls with a mean incorporation of $4310 \pm 292 \mathrm{cpm} / \mathrm{mg}$ lung/ $\mathrm{hr}$. As illustrated graphically in Figure 1, lung slices from control fetuses of 16-20 dg exhibit a relatively constant and low rate of $\left[{ }^{14} \mathrm{C}\right]$ choline incorporation, but augmentation of the pathway after 20 days. Thus, lungs from normal rat fetuses of $21 \mathrm{dg}$ with a rate of $3650 \pm 230(n=11)$ demonstrate significantly higher $(P$ $<0.001)\left[{ }^{14} \mathrm{C}\right]$ phosphatidylcholine formation when compared to the mean level in lung slices from control animals of $19.5 \mathrm{dg}$ $(2090 \pm 180 ; n=7)$. Anencephalic littermates of the latter group at $19.5 \mathrm{dg}$ did not differ significantly from control fetuses and were not studied at earlier stages of development.

In an attempt to overcome the metabolic effects of adrenocortical insufficiency, we treated anencephalic fetuses for 6-12 hr with pharmacologic doses of the potent glucocorticoid, dexamethasone. The results of determinations of $\left[{ }^{14} \mathrm{C}\right]$ phosphatidylcholine formation in lung slices from such animals are shown in Table 1 and in Figure 2. It is evident that enhancement in choline pathway activity could be achieved using this approach

Table 1. Phosphatidylcholine $(P C)$ production rates and cholinephosphotransferase (CPT) activities in lungs from normal and anencephalic rat fetuses of 20.5-22 days if gestation ${ }^{1}$

\begin{tabular}{|c|c|c|}
\hline Group of fetuses & $\begin{array}{c}\text { PC synthesis from } \\
{\left[{ }^{14} \mathrm{C}\right] \text { choline, } \mathrm{cpm} / \mathrm{mg}} \\
\text { lung/hr }\end{array}$ & $\begin{array}{c}\mathrm{CPT}, \underset{\mathrm{pmol} / \mathrm{min} / \mathrm{mg}}{\text { protein }} \\
\text {. }\end{array}$ \\
\hline Control & $3980 \pm 203(22)$ & $190 \pm 14(25)$ \\
\hline Anencephalic & $3050 \pm 268(20)^{2}$ & $120 \pm 9.2(13)^{3}$ \\
\hline $\begin{array}{l}\text { Anencephalic + } \\
\text { dexamethasone }\end{array}$ & $4630 \pm 585(15)^{4}$ & $340 \pm 20(16)^{5}$ \\
\hline
\end{tabular}

1 Mean $\pm \mathrm{SE}$; number of observations in parentheses.

${ }^{2} P<0.02$, as compared to control.

${ }^{3} P<0.001$, as compared to control.

${ }^{4} P<0.05$, as compared to the untreated anencephalic group but not significantly different from the control group.

${ }^{3} P<0.001$, as compared to both the untreated anencephalic group and the control fetuses.

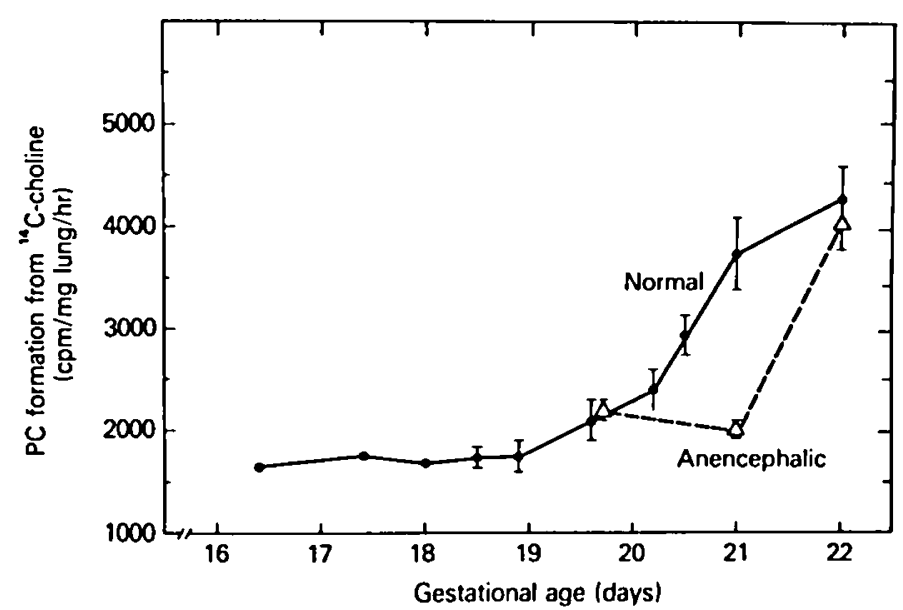

Fig. 1. Phosphatidylcholine $(P C)$ synthesis via the choline pathway in lung slices from control and anencephalic rat fetuses of various gestational ages. The pattern of the control fetuses was established with 49 animals (-). The anencephalic group (- - ) consisted of 23 fetuses. Mean values are shown with the brackets indicating SE. 


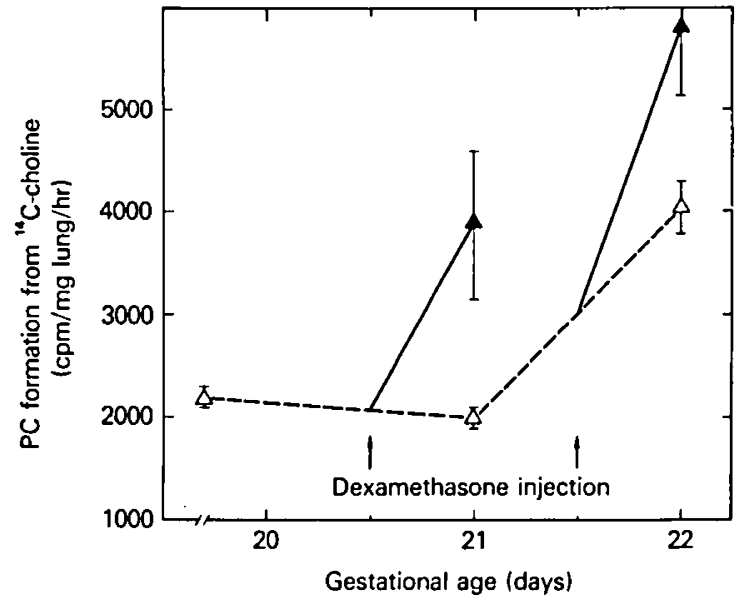

Fig. 2. Phosphatidylcholine $(P C)$ synthesis via the choline pathway in lung slices from untreated anencephalic fetuses and those administered dexamethasone in utero. $\Delta---\Delta$ : data from 23 anencephalic rat fetuses; $\Delta-\Delta$ : mean values observed in 15 corresponding animals given an intraperitoneal injection of dexamethasone and delivered 6-12 hr later. Brackets indicate SE.

with significant increases being demonstrable at both $21 \mathrm{dg}(P<$ $0.001)$ and $22 \mathrm{dg}(P<0.05)$. In fact, the mean rate of $\left[{ }^{14} \mathrm{C}\right]$ choline incorporation in steroid-treated anencephalic fetuses at $21 \mathrm{dg}$ was virtually indentical to that of controls and was even higher $(P<0.05)$ at term gestation $(5770 \pm 750 \mathrm{cpm} / \mathrm{mg}$ lung/hr; $n=6$ ) when compared to the level observed in control lungs. Thus, the group of dexamethasone-injected fetuses as a whole showed significantly higher pulmonary PC synthesis than the cortocosteroid-deficient group (see Table 1).

The results of cholinephosphotransferase determinations in lung homogenates from fetuses of $20.5-22 \mathrm{dg}$ are shown in Table 1. These measurements revealed that lungs from decapitated animals were considerably lower in mean enzyme activity than controls, but that CPT could be increased significantly by dexamethasone injection. Evaluation of tissue tritium content in anencephalic fetuses $6-12 \mathrm{hr}$ after $\left[{ }^{3} \mathrm{H}\right]$ dexamethasone injection revealed data indicating an average dexamethasone concentration of $135 \mathrm{pg} / \mathrm{mg}$ wet lung weight or $3.44 \times 10^{-7} \mathrm{M}$; this amounts to $4 \%$ of the injected dose. Although all 16 fetuses in this group showed measurable tritium, the levels varied considerably from animal to animal with the lowest being $3.5 \mathrm{pg} / \mathrm{mg}$ lung. Evaluation of lung $\left[{ }^{3} \mathrm{H}\right]$ dexamethasone content as compared to CPT activity suggested a possible correlation or doseresponse relationship. Eight fetuses with estimated dexamethasone concentrations of less than $10 \mathrm{pg} / \mathrm{mg}$ lung tended to show lower enzyme activities with a mean of $290 \mathrm{pmol} P C$ formed/ $\mathrm{min} / \mathrm{mg}$ protein than the remaining fetuses with corresponding values of $264 \mathrm{pg} / \mathrm{mg}$ and $380 \mathrm{pmol} / \mathrm{min} / \mathrm{mg}$ protein. Nonetheless, graphic comparison of the two parameters failed to verify a statistical correlation and all dexamethasone-treated anencephalic fetuses exhibited higher CPT activities than corticosteroid-deficient animals.

Electron microscopic examination of lungs from untreated anencephalic fetuses revealed impaired cytodifferentiation, as described in detail elsewhere (4). When such animals were exposed to dexamethasone for 6-12 hr, their lungs showed no differences in appearance, $i . e .$, no acceleration in morphologic development. Of particular interest was the lack of ultrastructural change in alveolar type II pneumonocytes.

\section{DISCUSSION}

Although it has been established that glucocorticoid administration to fetal animals accelerates pulmonary biochemical "maturation" (8), very little information is available on the state of lung development in fetuses with adrenocortical deficiency. To study the role of endogenous fetal corticoids, Vidyasagar and Chernick (24) and Kling and Kotas (20) have recently utilized maternal injection of Metopirone to block $11 \beta$-steroid hydroxylase activity and produce glucocorticoid deficiency in rabbit and baboon fetuses, respectively. Their findings on examining fetal lung tissue suggested delayed maturation but were not consistent in terms of effects on surface tension-lowering material. on pressure-volume hysteresis, and on the synthesis. storage. and secretion of phosphatidylcholine. The conflicting observations noted with the Metopirone model may be attributable to a number of factors, including inadequate adrenal suppression. cortisol rebound between injections, and the timing of Metopirone administration. The other experimental approach to producing fetal adrenocortical insufficiency by surgical decapitation has proven useful in studies concerned with the biochemical regulation of liver glycogen synthesis in rats $(15,18)$. This model permits satisfactory fetal growth (4) and has a counterpart in humans, viz., congenital anencephaly of genetic etiology. As mentioned previously, studies by Blackburn et al. (2-4) have demonstrated that fetal anencephaly in rats is accompanied by retarded lung development based on impaired cytodifferentiation, high surface tension of lung extracts, and low pulmonary PC concentration. In the present investigation, we have extended those observations by assessing selected biochemical features of lung differentiation in late gestation.

Plasma corticosterone, the principal circulating glucocorticoid of the rat, was measured in representative control and anencephalic fetuses. Whereas control littermates showed levels approximating the normal values reported by Cohen (5), pooled plasma samples from decapitated fetuses of 20 and 22 days of gestation had lower corticosterone concentrations averaging 7.7 $\mu \mathrm{g} / \mathrm{dl}$. The fact that circulating corticosteroids are not absent in the latter fetuses can probably be attributed to small but significant transplacental passage of steroid from the mother. Maternal adrenalectomy in association with fetal decapitation has been employed by some (16) to prevent this phenomenon but such a practice leads to increased mortality rates. Since the anencephalic fetuses from the single surgical procedure are low in circulating glucocorticoid and show hypoplasia of the adrenal cortex (17), we have preferred this approach and model of adrenocortical deficiency. It should be noted, however, that the model lacks hormonal specificity and essentially represents panhypopituitarism. For this reason, responses to hormone replacement are of great importance in assessing the significance of a biochemical abnormality in a target tissue such as fetal lung where corticosteroid receptors are present in high concentrations (13).

The primary biochemical mechanism for de novo synthesis of lung phosphatidylcholine, i.e., the choline incorporation pathway, shows increased activity in normal fetuses during late gestation $(7,10)$. This pathway was assessed in anencephalic fetuses using lung slices incubated in the presence of $\left[{ }^{1+} \mathrm{C}\right]$ choline. It was observed (Table 1 and Fig. 1) that corticosteroid-deficient animals exhibit significantly reduced choline incorporation at 21 but not 22 days of gestation. In comparison with control fetuses. the pattern observed represents a delay of approximately $2+\mathrm{hr}$ before enhancement in choline pathway activity occurs. Such a delay is consistent with, and likely the cause of, the lower PC concentration in lungs of these animals at term gestation (3). Treatment of decapitated fetuses in utero with dexamethasone markedly increased the choline incorporation rates to normal levels. Thus, it appears that corticosteroids act to influence the timing of biochemical "differentiation" relative to PC synthesis.

In keeping with reduced choline incorporation rates, the terminal enzyme of the pathway, cholinephosphotransferase, showed significantly decreased activity in lungs from anencephalic fetuses of 20.5-22 days of gestation. Since this abnormality could be corrected within $6-12$ hr by dexamethasone injection, and since glucocorticoids have been shown previously to have the capability of inducing CPT (11), we are led to conclude that glucocorticoid deficiency was responsible for the low en- 
zyme activity. These observations therefore support the concept that lung cholinephosphotransferase activity is responsive to corticosteroids (19). Other enzymes, however, such as lipoprotein lipase (14), are also increased in lung tissue following corticoid administration and may also serve as important regulatory factors controlling PC biosynthesis in developing lung.

Attempts in the past to establish a dose-response relationship between corticosteroids and the biochemical or physiologic events of lung maturation have proved difficult $(19,25)$. This may be partially attributable to the imperfect techniques used for injecting hormone preparations $(11,19)$. For this reason, we added $\left[{ }^{3} \mathrm{H}\right]$ dexamethasone to unlabeled glucocorticoid, measured lung tritium, and estimated the concentration of exogenous corticosteroid in lung tissue. This approach further suggested, but failed to establish, a correlation between the dose injected and the magnitude of enhanced CPT activity. The findings did indicate, however, that cholinephosphotransferase could be augmented with lung dexamethasone levels as low as $10^{-7} \mathrm{M}$.

Ultrastructural assessment of lungs from steroid-treated anencephalic fetuses did not reveal evidence of enhanced cytodifferentiation 6-12 hr after injection. Accelerated cytodifferentiation, however, can be demonstrated at 22 days of gestation when decapitated animals are injected $48 \mathrm{hr}$ earlier with pharmacologic doses of dexamethasone (W. R. Blackburn, unpublished observations). Thus, the sequence of events appears to be such that structural changes temporally follow those of a biochemical nature. These findings, therefore, support the proposal that although a 6-12-hr exposure to exogenous glucocorticoid is sufficient for enzyme induction and choline pathway activation, morphologic development of the respiratory units essential for air breathing, as well as accumulation of lung PC and surfaceactive material, require approximately $48 \mathrm{hr}(8,11,19)$. This temporal relationship seems to be of clinical importance since observations in human studies indicate that adequate functional development of the fetal lung is not evident until $24-48 \mathrm{hr}$ after glucocorticoids have been administered in an attempt to prevent the respiratory distress syndrome of premature infants $(8,21)$.

\section{REFERENCES AND NOTES}

1. Avery, M. E.: The Lung and Its Disorders in the Newborn Infant, p. 191 (W. B. Saunders Co., Philadelphia, 1974)

2. Blackburn, W. R., Kelly, J. S., Dickman, P. S., Travers, H., and Lopata, M. A.: The role of the pituitary-adrenal-thyroid axes in lung differentiation. II. Biochemical studies of developing lung in anencephalic rats. Lab. Invest. 28: 352 (1973)

3. Blackburn, W. R., Potter, D. M., Travers, H. Gassenheimer, L., and Rhoades, R. A.: Fetal rat lung development lipids and surface tension properties after decapitation in utero. Proc. Soc. Exp. Biol. Med., 140: 885 (1972).

4. Blackburn, W. R., Travers, H., and Potter, D. M.: The role of the pituitaryadrenal-thyroid axes in lung differentiation. I. Studies on the cytology and physical properties of anencephalic fetal rat lung. Lab. Invest., 26: 306 (1972).

5. Cohen, A.: Plasma corticosterone concentration in the foetal rat. Horm. Metab. Res., S: 66 (1973).

6. Ekelund, L., Arvidson, G., and Astedt, B.: Cortisol-induced accumulation of phospholipids in organ culture of human fetal lung. Scand. J. Clin. Lab. Invest., 35: 419 (1975).

7. Epstein, M. F., and Farrell, P. M.: The choline incorporation pathway: Primary mechanism for de novo lecithin synthesis in fetal primate lung. Pediat. Res., 9: 658 (1975).

8. Farrell, P. M., and Avery, M. E.: Hyaline membrane disease. Amer. Rev. Resp. Dis., 111: 657 (1975).

9. Fartell, P. M., Epstein, M. F., Fleischman, A. R., Oakes, G. K., and Chez, R. A.: Lung lecithin biosynthesis in the nonhuman primate fetus: Determination of the primary pathway in vivo. Biol. Neonate, 29: 238 (1976).

10. Farrell, P. M., Lundgren, D. W., and Adams, A. J.: Choline kinase and choline phosphotransferase in developing fetal rat lung. Biochem. Biophys. Res. Commun., 57: 696 (1974).

11. Farrell, P. M., and Zachman, R. D.: Induction of choline phosphotransferase and lecithin synthesis in the fetal lung by corticosteroids. Science, 179: 297 (1973).

12. Folch, J., Lees, M., and Stanley, G. H. S.: A simple method for the isolation and purification of total lipids from animal tissues. J. Biol. Chem., 226: 497 (1957).

13. Giannopoulos, G.: Variations in the levels of cytoplasmic glucocorticoid receptors in lungs of various species at different developmental stages. Endocrinology, 94: 450 (1974).

14. Hamosh, P., Hamosh, M., Yeager, H., and Schechter, Y.: Effect of dexamethasone on lipoprotein lipase activity of the rat lung. Fed. Proc., 35: 600 (1976).

15. Jacquot, R., and Kretchmer, N. J.: Effect of fetal decapitation on enzymes of glycogen metabolism. J. Biol. Chem., 239: 1301 (1964).

16. Jost, A.: Problems of fetal endocrinology: The adrenal glands. Recent Progr. Horm. Res., 22: 541 .

17. Jost, A., Dupouy, J. P., and Monchamp, A.: Fonction corticotrope de l'hypophyse et hypothalamus chez le foetus de rat. C. R. Acad. Sc. Paris, 262: 147 (1966).

18. Jost, A., and Picon, L.: Hormonal control of fetal development and metabolism. Advan. Metab. Disord., 4: 123 (1970).

19. Kotas, R. V., Fletcher, B. D., Torday, J., and Avery, M. E.: Evidence for independent regulations of organ maturation in fetal rabbits. Pediatrics, 47: 57 (1971).

20. Kling, O. R., and Kotas, R. V.: Endocrine influences on pulmonary maturation and the lecithin/sphingomyelin ratio in the fetal baboon. Amer. J. Obstet. Gynecol., 121: 664 (1975).

21. Liggins, G. C., and Howie, R. N.: A controlled trial of antepartum glucocorticoid treatment for prevention of the respiratory distress syndrome in premature infants. Pediatrics, 50: 515 (1972).

22. Lowry, O. H., Rosebrough, N. J., Farr, A. L., and Randall, R. J.: Protein measurements with the Folin phenol reagent. J. Biol. Chem., 193: 265 (1951).

23. Murphey, B. E. P.: Some studies of the protein-binding of steroids and their application to routine micro and ultramicro measurement of various steroids in body fluids by competitive protein binding radioassay. J. Clin. Endocrinol. Metab., 27: 973 (1967).

24. Vigyasagar, D., and Chernick, V.: Effect of Metopirone on the synthesis of lung surfactant in does and fetal rabbits. Biol. Neonate, 27: 1 (1975).

25. Wang, N. S., Kotas, R. V., Avery, M. E., and Thurlbeck, W. M.: Accelerated appearance of osmiophilic bodies in fetal lungs following steroid infection. $J$. Appl. Physiol., 30: 362 (1971).

26. Requests for reprints should be addressed to: P. M. Farrell, M.D., National Institutes of Health, Bldg. 10, Rm. 13N260, Bethesda, Md. 20014 (USA).

27. Received for publication August 17, 1976.

28. Accepted for publication November 23, 1976. 